\title{
ANALYSIS OF BODY COLLISIONS AGAINST OBSTACLES
}

\author{
Maris Eiduks, Edgars Kovals, Janis Viba, Lauris Stals \\ Riga Technical University, Latvia \\ maris.eiduks@rtu.lv, edgars.kovals@gmail.com, janis.viba@rtu.lv, lauris.stals@gmail.com
}

\begin{abstract}
Collisions between solid objects in machine building, technology and everyday life are widespread. However, analysis of the movement of solid objects by analytical methods is difficult even in the case of plane motion. The main problem arises when the collision process occurs with several successive impulse points. Then the points of the collision contact move along the surface of the object. Therefore, the equation of the boundary conditions must be solved. In these cases, the only sensible option is to perform experimental investigations or simulations by computer programs. In the first part of this work, 3DOF's solid body movement is analysed in a vertical or horizontal plane with collisions against the walls of a fixed or moving endless mass container. Different body shapes with convex and concave sections are considered. Graphical analysis of displacements, velocities and accelerations is given. Opportunities for object orientation or transport on the bottom edge of the container are displayed. The second part deals with the movement of several solid bodies in a closed or open container. Opportunities and problems in the analysis of many DOF systems are shown. The third part of the thesis contains simple movement experiments that give good accuracy to theoretical modelling results. The difference can be explained by the properties of real objects, such as the change of the slip friction coefficient in the impact. The work results can be used in machine building and robot technology.
\end{abstract}

Keywords: collision, multibody simulation, vibrations, multipoint collisions.

\section{Introduction}

Simple few solid body collision mechanics can be analysed by using classical mechanics formulas and calculated analytically, or by using mathematical software like Mathcad or similar. At one point in the solid body collision process, if the task is getting more complicated, like with more specific bodies with various shapes and mechanical properties and boundaries, the solid body collision processes analytical solution is only possible in the case of complete motion analysis [1-4]. However, there are also many (up to seven) cases of collision in further discussed problems. To find them, it is necessary to know the initial condition of the movement, the body configurations and the material mechanical properties, nevertheless, it is important to estimate degrees of freedom in the model. It is necessary to use iterative calculations at the previous collision point for the series-type collision process, changing the initial state of the sub-steps [5].The question of how to analyse concurrent collisions at several points analytically is explored [6]. In all these cases there are the following problems [4-7]: one-sided impact interaction in the normal direction; stop the interaction in the equilibrium area; the tangential direction of the points of contact must be respected. Non-linear dynamics research plays a significant role in addressing vibro-impact systems. This includes analysis, optimization, and synthesis of nonlinear systems that expand non-harmonious forms of excitation forces and new nonlinearities in elastic and collision elements [8-11].

Despite these difficulties, the engineers invent and implement various technological processes with collisions of several large and small objects. For example, collision in vibro-transport, vibroseparation, vibro- polishing is widely used (Fig. 1.and Fig. 2.) [12;13], but it could be used in the same way for analysing any other multibody collisions. Today's environment is offering various solutions for this. In this article we will look at some possibilities of using Mathcad, Working Model 2D and other 3Dsimulation programs[14-17].

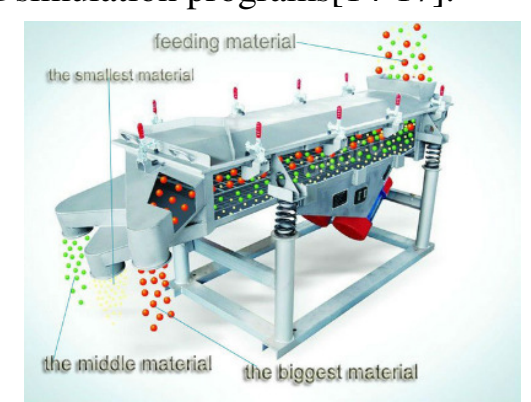

Fig. 1. Linear vibrating separator [12]

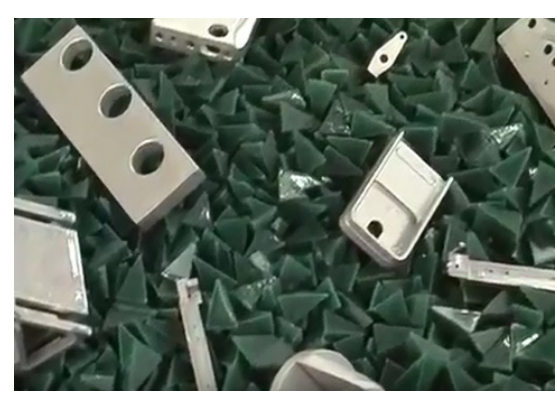

Fig. 2. Elements of vibro - polishing [13] 


\section{Materials and methods}

In this section, as the first method, the possibility of modeling the material layer motion with MathCAD is considered. It has been shown that selecting a very small integration step can be used as a sticking, sliding and jump mode. Accordingly, the next section of the Working Model 2D program shows an example of 60-degree system (60DOF) modeling. Here, periodic movement was found, as well as non-periodic movement of the system with variable structure. In the latter case, the number of degrees of freedom varies from 60DOF to zero.

\section{Flat container and flat material model analytical analysis method}

Bulk material model is shown in Fig. 3. For analytical calculation two degrees of freedom model can be used in the next form (1), (2):

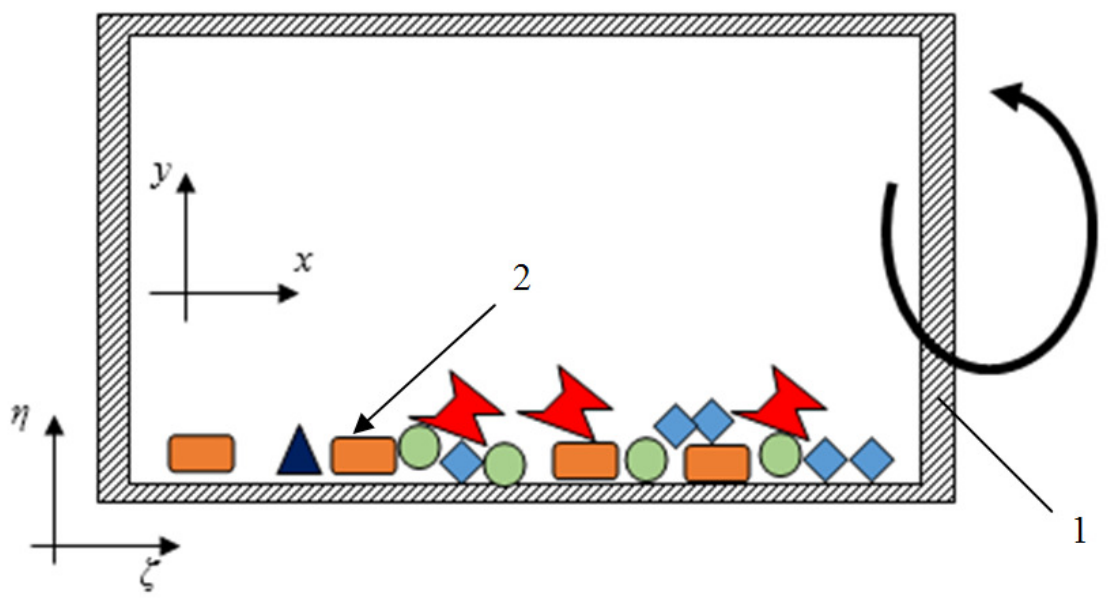

Fig. 3. Sample model: 1 - container; 2 - different parts of material

$$
\begin{gathered}
m \ddot{x}=-m g \cdot \sin (\alpha)-f \cdot N \cdot \operatorname{sign}(\dot{x})-b 0 \cdot v \cdot \dot{x}-a \varsigma, \\
m \ddot{y}=-m g \cdot \cos (\alpha)+N-b 0 \cdot v \cdot \dot{y}-a \eta,
\end{gathered}
$$

where $m$ - mass of bulk material;

$x, y, \dot{x}, \dot{y}, \ddot{x}, \ddot{y}$ - relative coordinates, relative velocity $v$ and relative acceleration components;

$g$ - free fall acceleration;

$\alpha$-containers surface angle along horizon;

$N$ - normal reaction;

$f$ - dry friction coefficient;

$b 0$ - air resistance coefficient;

$a \varsigma, a \eta$ - containers acceleration components.

For one - sided normal reaction $N$ the next relationship can be recommended (3):

$$
N=(-c \cdot y-b \cdot \dot{y}) \cdot(0.5+0.5 \cdot \operatorname{sign}(-c \cdot y-b \cdot \dot{y})),
$$

where $c, b$-one sided containers surface interaction elasticity and damping.

Some modelling results for only vertical containers harmonica motion are shown in Fig. 4-6.

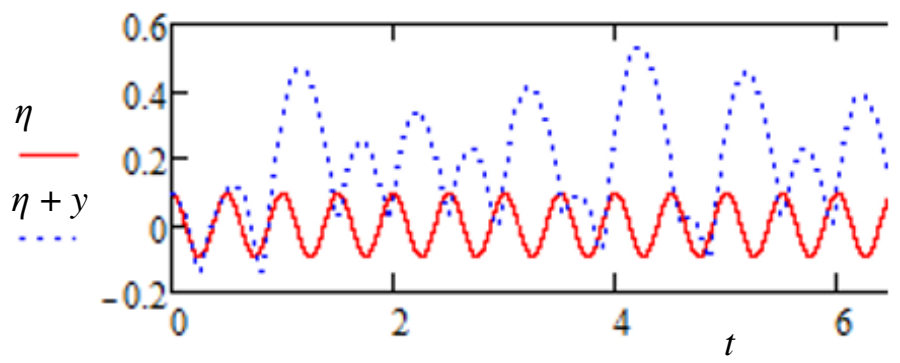

Fig. 4. Material vertical displacement $y$ at harmonic motion $\boldsymbol{\eta}$ of container 


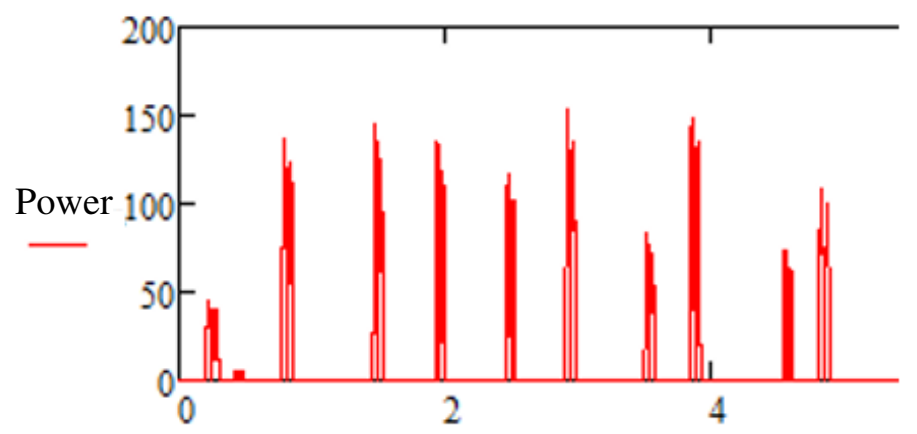

Fig. 5. Example of normal interaction $N$ generated power in system SI: $m=1 ; \alpha=0 ; c=1500 ; b=2 ; \max (a \eta)=1.5 \cdot g$

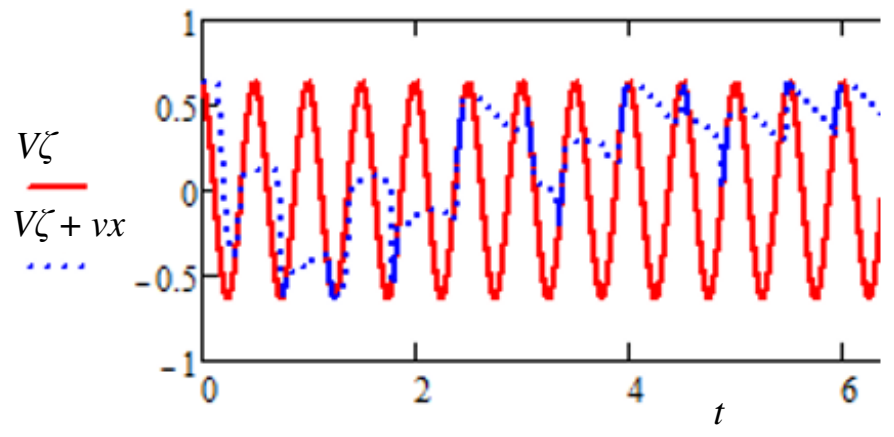

Fig. 6. Horizontal velocity components $V \zeta, v x$ of material at two components harmonic motion of container

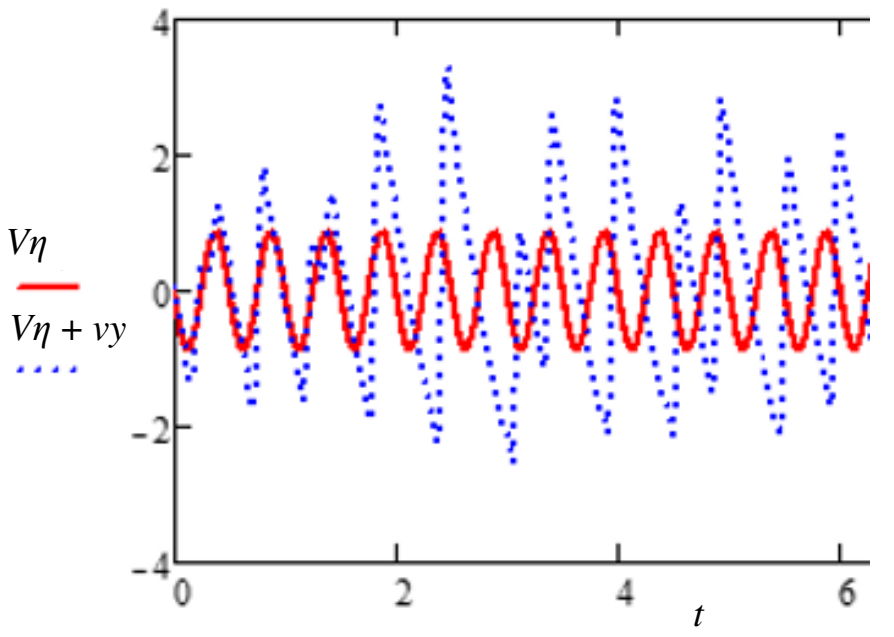

Fig. 7. Vertical velocity relative and absolute components $V \eta$, vy of material at two components harmonic motion of container

\section{Vibration analysis by Working Model $2 D$}

Similarly to the previously described analytical model analysis of similar systems to the previously mentioned in paragraph one can be modeled in various solutions that offer $2 \mathrm{D}$ visual simulations. For us Working Model 2D programme is available that allows to create forms of rigid bodies, defines body interactions and applied forces. Engineers by using this kind simulation are able to model similar or even more complex cases. In addition, to get the opportunity to monitor the process in visual representation and at the same time analyze each body and its interactions separately. The movement patterns of the processing and discharge processes are shown in Figures $8-12$. Comments on the movement of the container and the descriptions of the technological process are given below all images. 


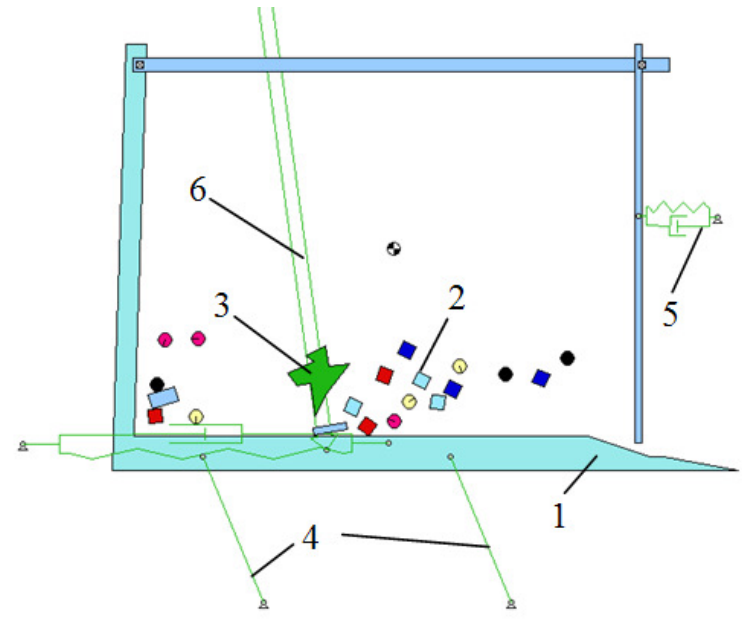

Fig. 8. Vertical flight mode for bulk material: 1 - container; 2 - processing material; 3 - polishing object; 4 - guide rods; 5 - spring system; 6 - circulating excitation force

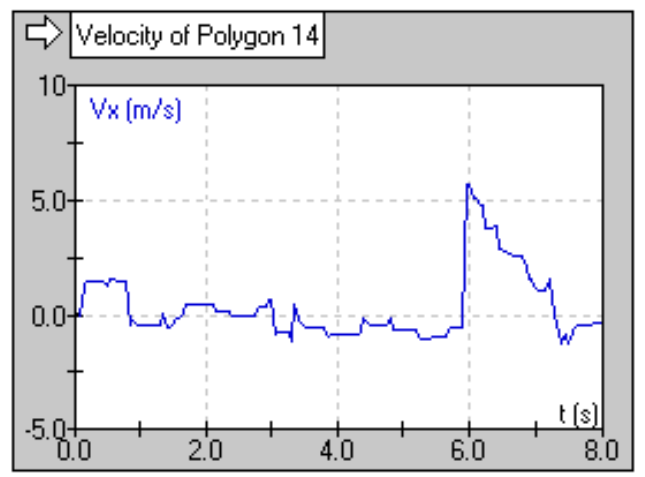

Fig. 10. Polygon horizontal velocity as function of time

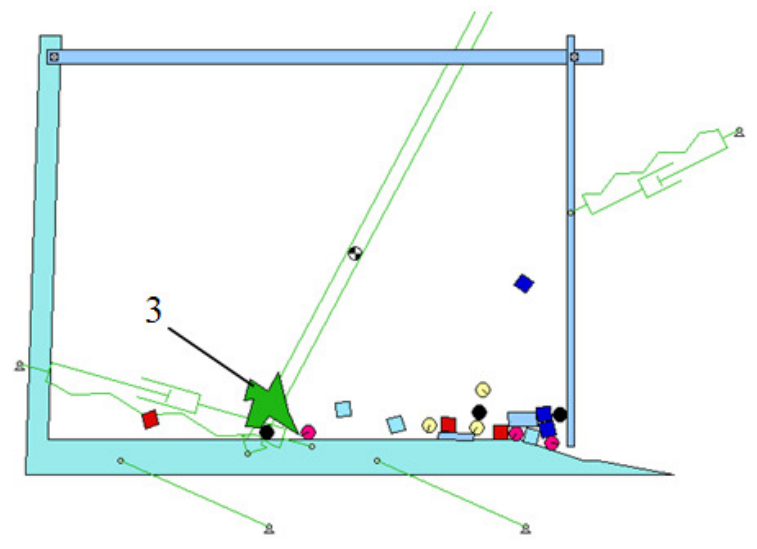

Fig. 9. Bulk material collision with container bottom: 3 - polishing object

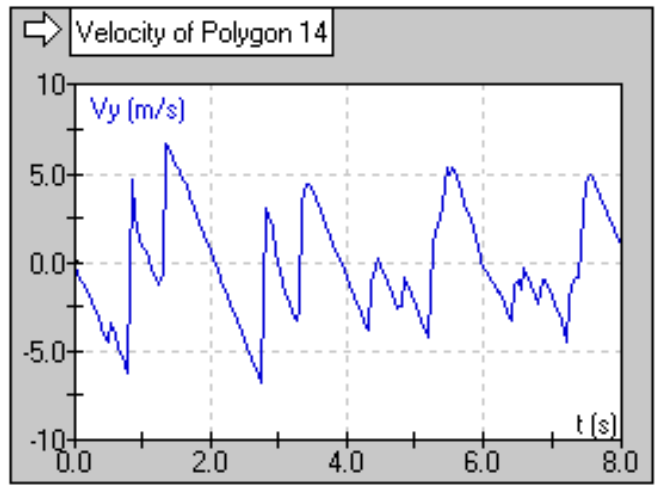

Fig. 11. Polygon vertical velocity as function of time

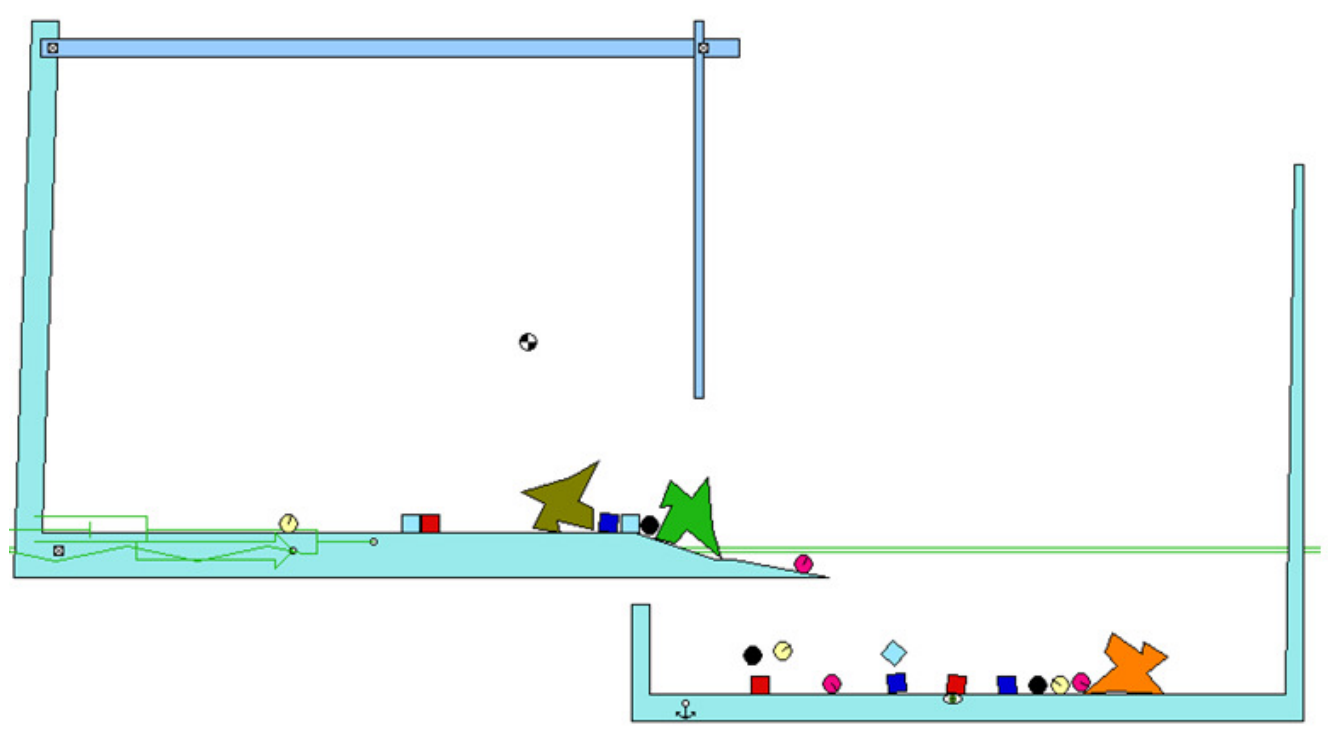

Fig. 12. Case of variable structure modeling, where number of degrees of freedom varies from 60 to zero 


\section{Results and discussion}

1. It is possible analytically to describe the collision processes of objects with the MathCAD program, if the rough material is viewed in the approximate movement of the mass center. It is shown that selecting a very small integration step can be used as a sticking, sliding and jump mode.

2. A harmonious force conveniently initiates the movement of a vertical vibrating container. It is possible to calculate the power of the process analytically.

3. For the modeling of complex movements, taking into account the collisions and impacts against the walls of the container, the use of the Working Model 2D is effective. Here, periodic movement was found, as well as non-periodic movement of the system with a variable structure, when the number of degrees of freedom varies from 60DOF to zero.

4. To get even more realistic visual representation of multibody collision interactions and processes in vibratory model nowadays it is very comfortable to use mechanical 3D simulation software that allows completely get visual representation and understanding of processes in the described model. Of course, it is very important to describe the model as realistically as possible, by leaving rigid body mechanics and defining the material elastic properties for each body.

5. Depending on the algorithms used and the model complicity, the body amount and defined task can be more computer resource esurient, but the awaited result, if the solution is found is most realistic and from the previously discussed modelling, the 3D solution gives real life representation of processes in the model.

6. One from the software that can be used is SOLIDWORKS Motion [17], where it is possible to create realistic 3D models of interacting bodies and define their real life mechanical properties. This software is using iterative solver that calculates each step based on the defined time step.

\section{Conclusions}

1. The MathCAD program can be applied in the analysis of the vibro-impact mechanisms, where a small computational step with sufficient accuracy can follow sliding, stopping, moving and bouncing of objects.

2. The MathCAD program allows optimization of the technological process by selecting the excitation parameters.

3. It has been shown that in the very complex analysis of collision processes till 60 degree of freedom and more, the use of the Working Model 2D program is effective.

4. The results and explanations from this study are useful for analyzing and synthesizing new technological processes that need to assess the effectiveness of many collision systems, including energy consumption or extraction.

\section{References}

[1] Плявниекс В.Ю. Расчет косого удара о препятствие (Body oblique impact against obstacle). Вопросы динамики и прочности (Problems of dynamics and strength: Collection of scientific articles, vol. 18). Riga: Zinatne, 1969, pp. 87-110. (In Russian).

[2] Плявниекс В.Ю. Косое соударение двух тел (Two-body oblique collision). Вопросы динамики и прочности (Problems of dynamics and strength: Collection of scientific articles, vol. 19). Riga: Zinatne, 1969, pp. 69-82. (In Russian).

[3] Плявниекс В.Ю. Пространственное соударение с переменным направлением скольжения (Spatial collision with a variable sliding direction). Вопросы динамики и прочности (Problems of dynamics and strength: Collection of scientific articles, vol. 21). Riga: Zinatne, 1971, pp. 37-46. (In Russian).

[4] Виба Я.А. Оптимизация и синтез виброударных машин (Optimization and synthesis of vibro impact machines). Riga: Zinatne, 1988, 252 p. (In Russian).

[5] Babitsky V.I. Theory of vibro-impact systems and applications. Berlin: Springer, 1998. $278 \mathrm{p}$.

[6] Viba J., Polukoshko S. Simultaneous collisions of rigid bodies in more than one point. Proceedings of the 4th international DAAAM conference "Industrial engineering - 
innovation as competitive edge for SME", 29-30th April 2004, Tallinn, Estonia, pp. 106-109.

[7] Ibrahim R.A. Vibro-impact dynamics: modeling, mapping and applications. Berlin: Springer, 2009. $217 \mathrm{p}$.

[8] Nan G. An analytical method for vibro-impact between shrouded blades under a multipleharmonic excitation. Journal of Vibroengineering, vol. 15, iss. 4, 2013, pp. 1947-1960.

[9] Banakh L. Contact problems in rotor systems. Vibroengineering Procedia, vol. 8, 2016, pp. 90-96.

[10]Li G., Ding W. Global behaviour of a vibro-impact system with asymmetric clearances. Journal of Sound and Vibration, vol. 423, 2018, pp. 180-194.

[11]Liu D., Li J., Meng Y. Probabilistic response analysis for a class of nonlinear vibroimpact oscillator with bilateral constraints under coloured noise excitation. Chaos, Solitons \& Fractals, vol. 122, 2019, pp. 179-188.

[12]Linear vibrating screen. [online] [07.05.2019]. Available at: http://www.vibrosieve.com/products/screening-equipment/linear-vibrating-screen.html

[13] Vibratory Finishing Machine. [online] [07.05.2019]. Available at: https://www.bing.com/videos/search?q = vibratory + finishing + machine

[14] MathCAD. [online] [07.05.2019]. Available at: https://mathcad.software.informer.com/

[15] Working Model 2D. [online] [07.05.2019]. Available at: http://www.design-simulation. $\mathrm{com} / \mathrm{wm} 2 \mathrm{~d} /$

[16] Working Model 3D. [online] [07.05.2019]. Available at: https://sourceforge.net/ directory/os: windows/?q = working + model $+3 \mathrm{~d}$

[17] SolidWorks Motion description. [online] [07.05.2019]. Available at: http://help.solidworks.com/2019/English/SolidWorks/SWHelp_List.html?id = caecf36286 894c639db9ff3bc7baf8ef\#Pg0 